\title{
PENGARUH KOMPOS TERHADAP HASIL PANEN TOMAT (Lycopersicum esculentum Mill)
}

\section{INFLUENCE OF COMPOST ON THE YIELD OF TOMATO (Lycopersicum esculentum Mill)}

\author{
Ahmad Raksun* dan I Gde Mertha \\ Program Studi Pendidikan Biologi, Fakultas Keguruan dan Ilmu Pendidikan, Universitas Mataram. \\ Jalan Majapahit no 62 Mataram, Lombok, 83125, Indonesia \\ *Email: ahmadunram@unram.ac.id
}

Diterima: 28 Februari 2018. Disetujui: 28 Maret 2018. Dipublikasikan: 31 Maret 2018

\begin{abstract}
Abstrak: Penelitian tentang pengaruh kompos terhadap hasil panen tomat, telah dilaksanakan di Desa Montong Are Kabupaten Lombok Barat. Tujuan dilaksanakannya penelitian ini adalah untuk mengetahui: (1) pengaruh pemberian kompos terhadap hasil panen tomat pada lahan pertanian Desa Montong Are, (2) dosis kompos yang perlu diberikan pada lahan pertanian Desa Montong Are agar tomat dapat berproduksi secara optimal. Dalam penelitian ini digunakan rancangan acak lengkap dengan enam ulangan. Data penelitian dianalisis dengan analisis sidik ragam dan uji lanjut dengan Uji Beda Nyata Terkecil (BNT). Hasil penelitian menunjukkan bahwa (1) aplikasi kompos pada lahan pertanian Desa Montong berpengaruh signifikan terhadap hasil panen tomat, (2) kadar optimum kompos yang perlu diberikan pada lahan pertanian Desa Montong Are agar tomat berproduksi secara optimal adalah $1,2 \mathrm{~kg}$ untuk setiap $10 \mathrm{~kg}$ tanah.
\end{abstract}

Kata kunci: kompos, hasil panen, dan tomat

\begin{abstract}
Study on the influence of compost on the yield of tomato was carried out in Montong Are Village West Lombok. The objective of this research are: (1) to identify the effect of the use of compost on the yield of tomato, (2) to identify the optimum dosage of compost that must be added to the soil of Montong Are farmland in order that tomato can product optimally. Completely randomized design with six replicates was used in this research. Data analysis with Anova and least significant difference test (LSD).The result of this research are: (1) the application of compost has a significant effect on the yield of tomato, (2) the optimum dosage of compost that must be given to the soil of Montong Are farmland in order that tomato can product optimally is $1.2 \mathrm{~kg}$ compost/10 kg soil.
\end{abstract}

Keywords: compost, yield and tomato

\section{PENDAHULUAN}

Penelitian tentang pengaruh pemberian pupuk terhadap tanaman telah banyak dilakukan sebelumnya [1-7]. Salah satu pupuk yang biasa diaplikasikan di tanaman adalah pupuk kompos. Kompos adalah pupuk organik yang dapat dibuat dengan bahan baku sampah organik. Pemberian pupuk organik dapat memperbaiki sifat fisik, kimia dan biologi tanah [8].Pemberian pupuk organik pada lahan pertanian sangat penting dalam menjaga kesuburan tanah dan pertumbuhan tanaman. Sifat fisik, kimia dan biologi tanah yang baik berpengaruh positif terhadap pertumbuhan dan produksi tanaman. Hasil penelitian Maruli [9] menunjukkan bahwa pemberian kompos berpengaruh nyata terhadap tinggi tanaman, umur berbunga, umur panen dan berat buah cabai rawit. Pemberian kompos berpengaruh nyata terhadap tinggi tanaman, panjang daun, lebar daun, diameter batang, waktu muncul bunga jantan dan bunga betina, panjang tongkol dan jumlah biji tanaman jagung manis [10]. Aplikasi beberapa pupuk organik pada tanaman caisim (Brassica campestris var. chinensis L) dapat meningkatkan tinggi batang, panjang daun, lebar dan berat basah daun [11].
Demikian juga Sayekti [12] menjelaskan bahwa aplikasi pupuk organik dalam bentuk pupuk kandang dan kompos mampu meningkatkan pertumbuhan kangkung dan lele dumbo pada sistem akuaponik.

Berdasarkan uraian di atas maka peneliti melakukan penelitian tentang pengaruh kompos terhadap hasil panen tanaman tomat yang dilakukan di Desa Montong Are Kecamatan Kediri Kabupaten Lombok Barat. Adapun tujuan dilaksanakannya penelitian ini adalah untuk mengetahui: (1) pengaruh pemberian kompos terhadap hasil panen tanaman tomat, (2) dosis optimum kompos yang perlu diberikan pada lahan pertanian Desa Montong Are agar tomat dapat berprokduksi secara optimal.

\section{METODE PENELITIAN}

Penelitian ini diawali dengan pembuatan kompos dengan bahan baku kotoran sapi. Adapun alat-alat yang digunakan adalah ember plastik, terpal, cangkul, linggis, karung goni, karung nilon, parang, sekop, sendok, dan gelas ukur. Selanjutnya bahan yang digunakan adalah kotoran sapi, dedak halus, sekam, dan air. Kegiatan berikutnya adalah pemanfaatan kompos untuk memupuk tanaman 
tomat. Alat-alat yang digunakan adalah pot plastik, alat tulis menulis, cangkul, ember plastik, timbangan, parang, hand spreyer dan gunting. Selanjutnya bahan-bahan yg digunakan adalah benih tomat, kertas label, tanah sawah, insektisida dan air. Setiap benih tomat ditanam pada pot plastik yang berisi $10 \mathrm{~kg}$ tanah yang dicampur dengan kompos sesuai dosis perlakuan

Dalam penelitian ini digunakan rancangan acak lengkap. Perlakuan kompos terdiri atas 7 level yaitu: $\mathrm{K}_{\mathrm{o}}=$ tanpa pemberian kompos (kontrol), $\mathrm{K}_{1}=$ pemberian $0,3 \mathrm{~kg}$ kompos, $\mathrm{K}_{2}=$ pemberian $0,6 \mathrm{~kg}$ kompos, $\mathrm{K}_{3}=$ pemberian $0,9 \mathrm{~kg}$ kompos, $\mathrm{K}_{4}=$ pemberian 1, $2 \mathrm{~kg}$ kompos, $\mathrm{K}_{5}=$ pemberian $1,5 \mathrm{~kg}$ kompos dan $\mathrm{K}_{6}=$ pemberian $1,8 \mathrm{~kg}$ kompos. Setiap perlakuan dilakukan dengan 6 ulangan sehingga diperoleh 7 × $6=42$ unit percobaan [13].

Parameter hasil panen yang diukur adalah berat basah buah tomat yang dipanen setelah matang. Panen buah tomat pertama kali dilakukan setelah tanaman berumur 78 hari. Data kuantitatif hasil pengukuran berat basah buah tomat dianalisis dengan analisis sidik ragam dan uji lanjut dengan Uji Beda Nyata Terkecil [14].

\section{HASIL PENELITIAN DAN PEMBAHASAN}

Percobaan tentang pengaruh kompos terhadap hasil panen tanaman tomat telah dilaksanakan di Desa Montong Are Kecanatan Kediri Kabupaten Lombok Barat Propinsi Nusa Tenggara Barat. Data hasil pengukuran berat basah buah tomat pada setiap perlakuan terdapat pada Tabel 1.

Tabel 1. Hasil pengukuran rerata berat basah buah tomat, pada setiap perlakuan akibat perlakuan kompos

\begin{tabular}{cc}
\hline Perlakuan & Berat Basah Buah (gr) \\
\hline $\mathrm{K}_{0}$ & 286 \\
$\mathrm{~K}_{1}$ & 312 \\
$\mathrm{~K}_{2}$ & 363 \\
$\mathrm{~K}_{3}$ & 382 \\
$\mathrm{~K}_{4}$ & 393 \\
$\mathrm{~K}_{5}$ & 390 \\
$\mathrm{~K}_{6}$ & 386 \\
$\mathrm{~K}_{7}$ & 380 \\
\hline
\end{tabular}

Hasil analisis data menunjukkan bahwa tomat yang ditanam pada unit percobaan tanpa perlakuan kompos memiliki rerata berat basah buah 286 gram. Selanjutnya pada media yang diberi kompos mulai dari pemberian $0,3 \mathrm{~kg}$ sampai dengan $1,2 \mathrm{~kg}$ kompos, rerata berat basah buah tomat mengalami peningkatan sejalan dengan meningkatnya dosis kompos yang diberikan pada masing-masing unit percobaan. Namun demikian mulai dari perlakuan $1,2 \mathrm{~kg}$ sampai dengan perlakuan 1,8 kg kompos, rerata berat basah buah tomat tidak menunjukkan adanya peningkatan secara nyata

Analisis sidik ragam pengaruh pemberian kompos terhadap berat basah buah tomat menunjukkan bahwa aplikasi kompos pada lahan pertania Desa Montong Are berpengaruh nyata terhadap meningkatnya berat basah buah tomat. Hal ini sesuai dengan hasil penelitian yang dilakukan oleh sejumlah peneliti sebelumnya. Dosis pupuk organik merpunyai pengaruh yang berbeda nyata terhadap tinggi tanaman pada umur 30 dan 45 hari setelah tanam, jumlah daun pada umur 45 hari setelah tanam, umur tanaman saat berbunga, umur tanaman saat panen, jumlah dan berat buah pertanaman terung [15]. Penggunaan pupuk kandang 75 gr pertanaman dapat meningkatkan kadar klorofil, berat segar akar, berat kering tajuk dan berat kering akar tanaman sambiloto [16]. Terdapat interaksi antara pupuk organik bokashi dan pupuk nitrogen terhadap jumlah daun, pemberian pupuk organik bokashi 10 ton/ha berpengaruh baik terhadap komponen kualitas bunga yaitu mampu menghasilkan tangkai bunga terpanjang dan jumlah kuntum bunga terbanyak [17]. Interkasi urea dan kompos berpengaruh nyata terhadap pertumbuhan jagung tongkol ganda [18]. Pemberian pupuk kompos mampu meningkatkan pertumbuhan dan produksi padi di lahan pasang surut sulfat masam [19], Perlakuan dosis pupuk organik berpengaruh sangat nyata terhadap tinggi tanaman umur 4 dan 8 minggu setelah tanam, jumlah dan berat buah tomat pertanaman [20]. Kedelai varietas galunggung merespon secara signifikan terhadap kompos limbah kelapa sawit, produksi meningkat secara sigifikan [21]. Pemberian pupuk kandang 5 ton/ha efektif meningkatkan hasil gabah padi varietas widas dan way apu buru [22]. Interaksi antara pupuk NPK dan pukpuk kompos memberikan pengaruh nyata terhadap pertumbuhan gmelina baik tinggi maupun diameter [23]. Penggunaan pupuk organik baik yang berasal dari kompos rami maupun pupuk kandang sapi dapat mengurangi pemakaian pupuk anorganik sebanyak $50 \mathrm{~kg} \mathrm{~N}$ perhektar [24]. Interaksi urea dan kompos berpengaruh nyata terhadap pertumbuhan jagung tongkol ganda.

Sejalan dengan hasil penelitian di atas, Arijal [25] menyimpulkan bahwa penggunaan bokashi eceng gondok dapat meningkatkan produksi padi gogo dan kedelai. Pemberian pupuk organik campuran pukan sapi, limbah ikan dan sludge dapat meningkatkan produksi kentang di Tapanuli Selatan [26]. Pemberian kompos berpengaruh nyata terhadap tinggi tanaman, umur berbunga, umur panen dan berat buah pertanaman. Syafriliandi [27] menyimpulkan bahwa pemberian kompos berpengaruh nyata terhadap tinggi tanaman, panjang daun, lebar daun, diameter batang, waktu muncul bunga jantan dan bunga betina, panjang tongkol dan jumlah biji tanaman jagung manis 
Rendahnya berat basah buah tomat, pada media tanpa aplikasi kompos disebabkan oleh kurang optimalnya ketersediaan berbagai unsur hara pada lahan pertanian Desa Montong Are. Selanjutnya pemberiaan bokasi menyebabkan makin tersedianya unsur hara terutama sulfat dan nitrat yang berasal dari hasil pengurain kotoran ternak yang diproses menjadi kompos. Disamping itu pemberian bokasi pada lahan pertanian dapat memperbaiki sifat fisika, kimia dan biologi tanah [2].

Hasil Uji Beda Nyata Terkecil menunjukkan bahwa kadar optimum bokashi yang perlu diberikan pada lahan pertanian Desa Montong Are Kecamatan Kediri Kabupaten Lombok Barat untuk meningkatkan produksi tanaman tomat adalah $1,2 \mathrm{~kg}$ kompos untuk setiap $10 \mathrm{~kg}$ tanah. Karena perlakuan dengan dosis 1,2 kg kompos/10 $\mathrm{kg}$ tanah memberikan tingkat hasil panen tomat yang terbaik dibandingkan perlakuan yang lain.

\section{KESIMPULAN}

Berdasarkan hasil analisis data dan pembahasan pada penelitian ini maka dapat disimpulkan bahwa: (1) Aplikasi kompos pada lahan pertanian Desa Montong Are berpengaruh nyata terhadap hasil panen buah tomat, (2) dosis optimum kompos yang perlu diberikan pada lahan pertanian Desa Montong Are agar tomat dapat berproduksi secara optimal adalah $1,2 \mathrm{~kg}$ kompos untuk $10 \mathrm{~kg}$ tanah

\section{DAFTAR PUSTAKA}

1. Raksun, A. (2018). Pengaruh Bokashi Terhadap Produksi Terong Ungu (Solanum melongena L.). Jurnal Biologi Tropis, 18(1), 21-26.

2. Raksun, A. (2009). Pengaruh Pemberian Bokashi Terhadap Pertumbuhan Dan Produksi Jagung (Zea mays). Jurnal Pijar Mipa, 4(2).

3. Raksun, A. (2014). Aplikasi Pupuk Organik Cair Untuk Meningkatkan Pertumbuhan Kedelai (Glycine max L.). Jurnal Biologi Tropis, 14(1).

4. Raksun, A. (2016). Aplikasi Pupuk Organik Untuk Meningkatkan Pertumbuhan Bibit Jambu Mete (Anacardium Occidentale L.). Jurnal Biologi Tropis, 16(2).

5. Raksun, A., \& Mertha, I. G. (2017). Pengaruh Bokashi Terhadap Produksi Cabai Rawit (Capsicum annuum). Jurnal Biologi Tropis, 17(2).

6. Japa, L., Raksun, A., Karnan, K., \& Santoso, D. (2018). Implementasi Biofermentasi "Effective Microorganism" Dalam Pengolahan Sampah Pertanian Dan Peternakan Untuk Meningkatkan Pertumbuhan Tanaman. Jurnal Pendidikan dan Pengabdian Masyarakat, 1(1).
7. Ilhamdi, M. L., Hadiprayitno, G., \& Suana, I. W. (2016, January). Pengembangan Sayuran Organik Menggunakan Teknologi EM4 (Effective Microorganism 4) di Desa Lembuak, Kecamatan Narmada. In Prosiding Seminar Biologi (Vol. 12, No. 1, pp. 906-910).

8. Musnamar, E.I. (2003). Pupuk Organik Padat. Penebar Swadaya. Jakarta.

9. MP, E. (2012). Pengaruh Pemberian Npk Grower Dan Kompos Terhadap Pertumbuhan Dan Produksi Tanaman Cabe Rawit (Capsicum Frutescent L). Dinamika Pertanian, 27(3), 19-26.

10. Kresnatita, S., Koesriharti, K., \& Santoso, M. (2012). Pengaruh rabuk organik terhadap pertumbuhan dan hasil tanaman jagung manis. The Indonesian Green Technology Journal, 1(3), 8-17.

11. Abuyamin. 2016. Pengaruh Pemberian Urin Kelinci dan Kompos terhadap Pertumbuhan dan Hasil Tanaman Caisim (Brassica juncea L.). Plumula. Vol 5 (1) p. $69-79$

12. Rahmi, S. (2016). Pengaruh Komposisi Pupuk Kandang Dan Kompos Terhadap Pertumbuhan Dan Hasil Kangkung (Ipomea reptans) Akuaponik. Jurnal Teknologi Lingkungan, 17(2), 108-117.

13. Hanafiah, K.A. 1994. Rancangan Percobaan. Teori dan Aplikasi. Fakultas Pertanian Universitas Barawijaya. Palembang.

14. Gomez K.A. dan A.A. Gomez. (1995). Prosedur Statistik Untuk penelitian Pertanian Edisi Kedua Penerjemah: Endang Syamsudin dan Justika S. Baharsyah. UI Press. Jakarta.

15. Safei, M., Rahmi, A., \& Jannah, N. (2014). Pengaruh jenis dan dosis pupuk organik terhadap pertumbuhan dan hasil tanaman terung (Solanum melongena L.) varietas Mustang F-1. AGRIFOR, 13(1), 59-66.

16. Pujiasmanto, B., Sunu, P., Toeranto, T., \& Imron, A. (2013). Pengaruh Macam dan Dosis Pupuk Organik terhadap Pertumbuhan dan Hasil Tanaman Sambiloto (Andrographis paniculata Ness.). Sains Tanah-Journal of Soil Science and Agroclimatology, 6(2), 81-90.

17. Farida dan Hamdani, J.S. 2003. Pertumbuhan dan Hasil Bunga Gladiol Pada Dosis Pupuk Organik Bokashi dan Nitrogen yang Berbeda. Bionatura V. 3(2) p. 68 - 76

18. Muyassir. 2013. Respon Jagung Tongkol Ganda terhadap Pemupukan Urea dan Kompos. Manejemen Sumberdaya Lahan. Vol 2 (3) p. $250-254$

19. Indrayati, L. 2005. Pengolahan Jerami Padi pada Pertanaman Padi Lahan Pasang Surut Sulfat Masam. Abstrak Hasil Penelitian Pertanian Indonesia Pusat Perpustakaan dan Penyebaran Hasil Penelitian Indonesia. Vol. XII No.2. Bogor. 
20. Maryanto dan Rahmi, A. (2015). Pengaruh Jenis dan Dosis Pupuk Organik terhadap Pertumbuhan dan Hasil Tanaman Tomat. Agrifor. XIV (1), 87 - 94

21. Darma,S. (2000). Respon Tanaman Kedelai Terhadap Kompos Limbah Kelapa Sawit pada Dosis Berbeda. Budidaya Pertanian.6(2), 96 104

22. Budi, D.S. (2004). Perbaikan Produktivitas dan Mutu Hasil Padi Gogorancah Melalui Pemupukan Kalium dan Pengolahan Pupuk Kandang. Abstrak Hasil Penelitian Pertanian Indonesia Pusat Perpustakaan dan Penyebaran Hasil Penelitian Indonesia. Vol. XII No.2. Bogor.

23. Wasis, B. dan Fathia, N. (2010). Pengaruh Pupuk NPK dan Kompos terhadap Pertumbuhan Semai Gmelina (Gmelina arborea Roxb.). Ilmu Pertanian Indonesia. 16(2), 123 - 129

24. Krisnatita, S., Koesriharti dan Santoso, M. 2013. Pengaruh Rabuk Organik terhadap Pertumbuhan dan Hasil Tanaman Jagung Manis. Indonesian Green Tachnology. 2(1), 8 $-17$

25. Arijal, Pabinru, A.M., dan Ibrahim B. 2005. Penggunaan Bokashi Eceng Gondok Pada Sistem Pertanian Tunggal dan Tumpangsari Padi Gogo dan Kedelai. Sains \& Teknologi. 5(1), 27-36

26. Syafriliandi, Murniati dan Idwar. 2016. Pengaruh Jenis Kompos terhadap Pertumbuhan dan Produksi Tanaman Jagung Manis. Jom Faperta. 3(2), 1 - 9 